\title{
EDUCAÇÃO AMBIENTAL E NARRATIVA TRANSMÍDIA: PEDAGOGIA POPULAR E FENOMENOLOGIA RECRIANDO O ESPAÇO ESCOLAR
}

\author{
Michèle Sato ${ }^{1}$ \\ Benedito Dielcio Moreira ${ }^{2}$ \\ Thiago Cury Luiz ${ }^{3}$
}

\begin{abstract}
Resumo: O presente texto sumariza um projeto intitulado "Educomunicação, ciência e outros saberes: um estudo do trabalho colaborativo em narrativas transmídias", coordenado pela Universidade Federal de Mato Grosso em parceria com a Secretaria de Estado de Educação (Seduc). Nos anos de 2015 e 2016, o projeto atuou em nove escolas públicas [piloto] de Mato Grosso - urbanas e rurais -, trabalhando a construção coletiva do conhecimento em três grandes áreas intrinsecamente relacionadas: história, criatividade e Educação Ambiental. Tendo como motor a narrativa transmídia, professoras (es) e estudantes construíram e compartilharam os conhecimentos produzidos, arquitetando comunidades de aprendizagens. As intervenções nas escolas coadunam com os métodos participativos de Paulo Freire, e as interpretações dos resultados caminharam num horizonte fenomenológico de Merleau-Ponty.
\end{abstract}

Palavras-chave: Educação Ambiental; Narrativa transmídia; Educomunicação; fenomenologia.

\section{ENVIRONMENTAL AND TRANSMED NARRATIVE EDUCATION: POPULAR PEDAGOGY AND PHENOMENOLOGY RECRUING SCHOOL SPACE}

\begin{abstract}
This article summarizes a project entitled "Edu-communication, science and other knowledge: a study of collaborative work in storytelling", coordinated by the Federal University of Mato Grosso in partnership with State Secretary of Education. In 2015 and 2016, the project worked in nine [pilot] public schools of Mato Grosso - urban and rural -, working the collective construction of knowledge in three main areas that are intrinsically related: history, creativity and environmental education.Framed on storytelling, or transmedia narrative, teachers and students built and shared the knowledge by community learning process. Interventions in schools were based upon Paulo Freire's participatory methods, and the student's interpretations were understood by Merleau-Ponty's phenomenological approach.
\end{abstract}

Keywords: Environment Education; Storytelling; Transmedia narrative; Edu-communication; phenomenology.

\footnotetext{
${ }^{1}$ Professora do Departamento do Programa de Pós-graduação em Educação da Universidade Federal de Mato Grosso e pesquisadora do "Grupo Pesquisador em Educação Ambiental, Comunicação e Artes" da Universidade Federal de Mato Grosso.

2 Professor do Departamento de Comunicação Social da Universidade Federal de Mato Grosso e pesquisador do "Grupo Pesquisador em Educação Ambiental, Comunicação e Artes" da Universidade Federal de Mato Grosso.

${ }^{3}$ Professor do Departamento de Comunicação Social da Universidade Federal de Mato Grosso e pesquisador do "Grupo Pesquisador em Educação Ambiental, Comunicação e Artes" da Universidade Federal de Mato Grosso.
} 


\section{Introdução}

Talvez seja possível afirmar que, a partir da década de 90, a Comunicação foi uma área que revolucionou a civilização, apoiada pela expansão da Internet e corroborando com a teoria de que cada sujeito ${ }^{4}$ poderia se transformar em uma mídia. Em vista do papel que a Comunicação desempenha na sociedade, inclusive nas suas dimensões educativas, ambientais, éticas e políticas, a narrativa transmídia pode servir como elemento central da Educação Ambiental no processo pedagógico entre estudantes e professoras(es).

Partindo do princípio de que a transmidialização dos conteúdos fortifica um tripé importante do atual momento - convergência das mídias, inteligência coletiva e cultura participativa -, aliar o conceito oriundo da Comunicação com a Educação Ambiental viabiliza um modo diferente na pedagogia que se dá entre docentes e jovens estudantes. E tudo porque, com a adesão dessa modalidade de narrativa, a lógica tradicional da sala de aula dá lugar à dinâmica de produção e reflexão acerca do conhecimento por parte de educadoras(es) e educandas(os) conjuntamente. A transmidialidade é, por essência, freireana nas suas premissas e implementações.

É nesse momento, então, que entendemos ser a fenomenologia de MerleauPonty a opção metodológica - junto à pedagogia popular de Freire - mais adequada para pôr em funcionamento uma ideia com essas feições. Por considerar que o instante, o momento de percepção do fenômeno, traz a respeito dele características preciosas, a corrente filosófica em questão não se apega exclusivamente ao passado, nem tem a pretensão de controlar o futuro, algo que nas Ciências Humanas parece ser ainda mais improvável. Uma extração do tempo e do espaço, com as pessoas que os compõem, não tem representatividade a priori ou posteriori.

No âmbito do Grupo Pesquisador em Educação Ambiental, Comunicação e Arte (GPEA), há um leque de metodologias diferenciadas à pesquisa qualitativa. Mas as três mais frequentes relacionam-se aos campos conceituais: a) a pesquisa participante, com ênfase à educação popular e geralmente nas intervenções e coletivos que ocorrem fora da escola, construída de forma conjunta e entre saberes partilhados colaborativamente; b) a pesquisa fenomenológica, na interpretação dos fenômenos e por meio de diversos

\footnotetext{
${ }^{4}$ A ideia de sujeito usada por nós segue o entendimento de Paulo Freire sobre os indivíduos. 
autores, que convida o pesquisador ou a pesquisadora a se distanciar do coletivo para seus próprios pensamentos, valores e existências; e c) a pesquisa sociopoética e a cartografia do imaginário, que buscam diálogos entre a fenomenologia e a participante, que valoriza a construção de confeto (conceitos e afetos), do saber, fazer e sentir a educação ambiental com o corpo inteiro. Das oficinas grupais, dos diálogos de saberes populares e acadêmicos, da tentativa de construir epistemologias não meramente acadêmicas, nas esteiras das vivências com comunidades de aprendizagens e nas escolhas de valores, reflexões e axiomas éticos.

Assim, a conjugação entre Comunicação e Educação pode despontar como alternativa para compreender o contexto da crise generalizada que assola a Terra, e é o que tentaremos debater neste artigo. Costurando reflexão epistemológica e o caráter praxiológico das nossas incursões a partir do projeto de vivência comunitária intitulado "Educomunicação, ciência e outros saberes: um estudo do trabalho colaborativo em narrativas transmídias", faremos um inventário do que averiguamos no período de ação da pesquisa, sem a preocupação de encerrar a discussão, e sim fomentar outras imersões.

De igual modo, não é nosso intuito postular as atividades realizadas nas escolas e aqui relatadas como doutrina universal à educação, entendendo que os anseios variam de um lugar a outro. Enxergamos essas variantes a partir da fenomenologia. Na nossa própria pesquisa, observamos diferenças no desenvolvimento do trabalho em cada centro escolar. Apenas nos resguardamos a apresentar neste artigo uma maneira que julgamos pertinente de imbricar comunicação e educação. Essa junção viabiliza a multiplicidade de opiniões e formas de ver o mundo, ora concordantes, ora dissonantes entre si, algo que pode contribuir para os debates.

\section{A Educação Ambiental nos ventos da justiça climática}

O planeta tem passado por diversas mudanças climáticas ao longo de sua existência, contudo, com mais graves e acentuadas alterações nas últimas décadas, fator que obriga a sociedade a reconhecer o papel do Homo sapiens na mudança do clima, e repensar novas formas de se produzir uma nova ordem nos campos da economia, da política, da cultura - entendida aqui como hábito, costume, prática. 
Além disso, o desenvolvimento científico e tecnológico no manejo do solo propiciou ao sistema explorar as áreas rurais, jogando no solo uma quantidade considerável de agrotóxicos. Isso implica contaminação do lençol freático e dos alimentos que chegam às casas de todos nós. Novas e mais fortes doenças passam a desafiar a Medicina a criar tratamentos mais eficazes.

Além da natureza, a discussão acerca do meio ambiente também abrange as questões humanas. Se uma etnia indígena é deslocada de sua área de direito por pressão do agronegócio, temos aí um problema socioambiental. Se a um grupo quilombola é vetado o direito de habitar a terra garantida por lei, eis uma pendência socioambiental. Se a cultura de povos ribeirinhos é atentada de alguma forma, o meio ambiente exige uma resolução sustentável. Nesses casos, conservar o meio ambiente é militar em prol das minorias, das populações mais vulneráveis.

Para garantir direitos iguais a todos que convivem no mesmo espaço, uma comunidade, um país ou até o planeta, a economia tem papel relevante e os parâmetros ambientais, por sua vez, precisam ser respeitados para não haver excessos de um lado que prejudiquem grupos de maior vulnerabilidade. Se a democracia concede direitos aos indivíduos, os desrespeitos ambientais devem ser combatidos, pois subjugam espaços de convivência de grupos mais expostos aos efeitos negativos.

Diante da complexidade e importância apresentadas pelo meio ambiente, até como fundamento político e preservação e aprimoramento da democracia, o meio ambiente requer cuidado especial. Faz-se, então, necessário levar até a sociedade os pressupostos ambientais que precisam ser preservados.

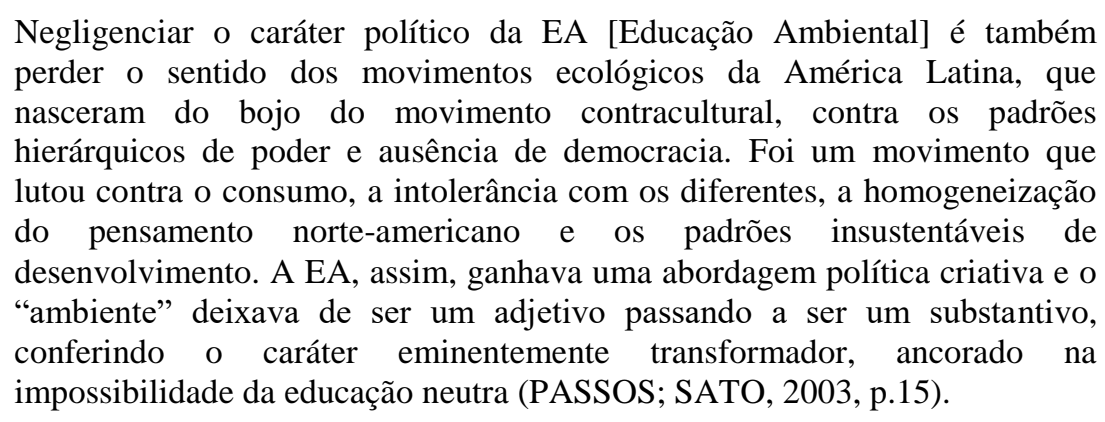

Nas palavras de Sato (2001, p.5), complementando a ideia que ela mesma em parceria com Passos apresentaram anteriormente, por nascer em cenário de revolução, de subversão do pensamento hegemônico e conservador, a EA apregoa uma metamorfose. 
A EA torna-se, assim, um substantivo composto, indissociável em sua essência ontoepistemológica, com dimensões não somente naturais, mas igualmente culturais. Valorizar a identidade da EA é, portanto, reconhecer que as duas dimensões são intrinsecamente conectadas e interdependentes, tornando os campos epistêmicos fortalecidos pelas lutas ambientalistas e movimentos sociais.

Pensando nas dimensões e características de Mato Grosso, trata-se de um local que apresenta diversidade ecológica distribuída em três biomas: Amazônia, Cerrado e Pantanal, além de um ecossistema denominado Araguaia. Fora os atrativos relativos às paisagens naturais, há as manifestações culturais cravadas em populações indígenas e na arte popular (JABER; SATO; SILVA, 2012, p.2).

Pensando nisso, o trabalho em comunidades rurais gera resultados satisfatórios, na medida em que estão em contato mais intenso com a natureza, diferente do que ocorre com as populações calcadas na industrialização, tecnologia e na forte urbanização.

As comunidades são importantes espaços educativos para a formação da cidadania e sustentabilidade, pois a partir delas podemos entender o ser e a natureza, que muitas vezes se integram a partir de regulações socioambientais formadas pelas observações dos ciclos da natureza. Entendemos como sentido de comunidade não apenas o território físico definido, mas como o território compartilhado do saber local, da interação com o outro, da tradição e da simbologia (MANFRINATE E SILVA; SATO, 2013, p.2).

Como os desafios da EA são muitos diante do processo de deterioração do meio ambiente, vejamos de que forma a Comunicação se alicerça e pode oferecer contribuições.

\section{A educação emancipadora na interação eu-outro-mundo}

No âmbito da Educação, acostumamo-nos com um modelo tradicional que se tornou hegemônico: a autoridade de uma pessoa - o(a) professor(a) - sobre os(as) demais presentes em sala de aula - os(as) alunos(as). $\mathrm{O}$ (a) docente habitualmente foi tido(a) como aquele(a) que detinha todos os conhecimentos, e como os(as) estudantes nada sabiam, deviam obediência ao mestre.

No sentido contrário, é pertinente colocar que quanto mais pessoas participam, de forma ativa, do processo de compartilhamento do conhecimento, aprimora-se a educação, tendo em vista que se apenas uma pessoa detém o saber, a chance de resvalar no equívoco é maior.

O conhecimento, sob forma de palavra, de ideia, de teoria, é o fruto de uma tradução/reconstrução por meio da linguagem e do pensamento e, por conseguinte, está sujeito ao erro. Este conhecimento, ao mesmo tempo tradução e reconstrução, comporta interpretação, o que introduz o risco do 
erro na subjetividade do conhecedor, de sua visão do mundo e de seus princípios de conhecimento. Daí os numerosos erros de concepção de ideias que sobrevêm a despeito de nossos controles racionais (MORIN, 2000, p.20).

Nesse contexto, o diálogo e a consequente troca de saberes se colocam na vanguarda por uma escola que faça adesão a outros valores, mais atuais. Paulo Freire, então, trouxe uma proposta, calcada em quem está na escola para aprender, mas que, por sua vivência específica, tem conhecimento a oferecer aos demais, inclusive ao professor.

Educador e educandos (liderança e massas), cointencionados à realidade, se encontram numa tarefa em que ambos são sujeitos no ato, não só de desvelála e, assim, criticamente conhecê-la, mas também no de recriar este conhecimento [...] Ao alcançarem, na reflexão e na ação em comum, este saber da realidade, se descobrem como seus refazedores permanentes. Deste modo, a presença dos oprimidos na busca de sua libertação, mais que pseudoparticipação, é o que deve ser: engajamento (FREIRE, 2014, p.77-78).

Segundo Freire (1996, p.29), no momento em que houver a equiparação dos sujeitos da educação - sem a hierarquia que é colocada nas instituições de ensino mais como forma de intimidação, de controle, menos como método eficaz -, o contato entre professor(a) e estudante estará regado de conhecimento. Sem a troca de saberes, a travessia da escola é inglória.

\begin{abstract}
Nas condições de verdadeira aprendizagem os educandos vão se transformando em reais sujeitos da construção e reconstrução do saber ensinado, ao lado do educador, igualmente sujeito do processo. Só assim podemos falar realmente de saber ensinado, em que o objeto ensinado é aprendido na sua razão de ser e, portanto, aprendido pelos educandos.
\end{abstract}

Assim, Freire entendia que a maneira mais eficiente de haver uma revolução nas estruturais sociais do país - desde sempre muito desiguais - era por meio da escola, na medida em que o oprimido fosse banhado pelo protagonismo do qual sistematicamente fora excluído. Capitaneados pela práxis, os subalternos poderiam ascender e se colocar em uma posição diferente. "A práxis, porém, é reflexão e ação dos homens sobre o mundo para transformá-lo. Sem ela, é impossível a superação da contradição opressoroprimidos" (FREIRE, 2014, p.52).

A práxis freireana pode ser alcançada pela educomunicação, campo de estudo que visa aliar as novas tecnologias da informação à pedagogia. Esse mecanismo contribui para uma participação mais ativa do estudante no processo de aprendizagem, garantindo a ele um protagonismo que até então lhe fora recusado.

Na perspectiva da educomunicação - definida como área da prática social preocupada com a natureza dos ecossistemas comunicativos em que os sujeitos sociais estão inseridos, objetivando não apenas garantir o acesso aos recursos da informação, mas essencialmente facilitar que o domínio dos 
novos instrumentos esteja sintonizado com um projeto político que garanta o exercício universal do direito à expressão, no contexto de uma sociedade solidária, que faça a cidadania prevalecer sobre o mercado -, o que importa identificar é o potencial transformador que se estabelece nas relações entre as novas gerações e as novas tecnologias (SOARES; VIANA, 2012, p.4).

Não de outro modo, consignar o ensino e o diálogo com a realidade traduzida, interpretada, reconstruída, com o cotidiano em vigor nas suas mais diversas manifestações. A ideia, para isso, de pavimentar o caminho entre pedaço e universo, transitando por idas e vindas, é como Morin (2000, p.38) concebe a educação.

O conhecimento pertinente deve enfrentar a complexidade. Complexus significa o que foi tecido junto; de fato, há complexidade quando elementos diferentes são inseparáveis constitutivos do todo (como o econômico, o político, o sociológico, o psicológico, o afetivo, o mitológico), e há um tecido interdependente, interativo e inter-retroativo entre o objeto de conhecimento e seu contexto, as partes e o todo, o todo e as partes, as partes entre si.

Talvez sem querer, Morin nos deu as chaves para entender e como encarar o desafio de preservar o meio ambiente e as suas orientações pedagógicas.

No panorama atual, notamos a mudança do sujeito da comunicação. Dessa forma, na definição de Henry Jenkins (2009, p.29), visualizamos a ocorrência de três novos fenômenos: convergência dos meios de comunicação, cultura participativa e inteligência coletiva. É nessa nova ordem que está sedimentada a narrativa transmídia.

Uma história transmídia desenrola-se através de múltiplas plataformas de mídia, com cada novo texto contribuindo de maneira distinta e valiosa para o todo. Na forma ideal de narrativa transmídia, cada meio faz o que faz de melhor - a fim de que uma história possa ser introduzida num filme, ser expandida pela televisão, romances e quadrinhos; seu universo possa ser explorado em games ou experimentado como atração de um parque de diversões. Cada acesso à franquia deve ser autônomo, para que não seja necessário ver o filme para gostar do game, e vice-versa. Cada produto determinado é um ponto de acesso à franquia como um todo (JENKINS, 2009, p.138).

Outra possibilidade da transmídia é dar continuidade em outras mídias aos materiais repletos de lacunas, criando-se as "franquias". Em Matrix, algumas respostas do enredo cinematográfico eram encontradas no game. Para cada aparelho, tem-se o desenrolar do conteúdo a partir de uma narrativa canônica, termo apresentado por Massarolo e Mesquita (2013, p.1).

\section{Práxis e fenomenologia se associam à narrativa transmídia: uma análise de caso em escolas públicas de MT}

De início, o projeto "Educomunicação, ciência e outros saberes: um estudo do trabalho colaborativo em narrativas transmídias" propôs trabalhar em oito escolas públicas de Mato Grosso, sendo quatro urbanas e quatro rurais. Como não houve acordo 
com uma delas, sete foi o número em que a atuação se deu na primeira fase. A ideia foi debater com o professorado e os estudantes uma nova relação didático-pedagógica na sala de aula e transcender esse espaço por entender que as dinâmicas de ensinoaprendizagem podem se dar em outros cenários.

De agosto de 2015 a dezembro de 2016, a proposta foi encampada pela Secretaria de Estado de Educação (Seduc) como política pública. A Universidade Federal de Mato Grosso, por intermédio do Departamento de Comunicação Social, na pessoa do professor doutor Benedito Dielcio Moreira, idealizou o projeto, que, por meio da Uniselva, foi contemplado com verba pública. Como os recursos financeiros para o desenvolvimento do projeto chegaram somente em dezembro do primeiro ano, professores e alunos/as, de agosto a dezembro, desenvolveram o projeto com recursos próprios, e transporte para o deslocamento cedido pela UFMT. Em 2016, o projeto piloto foi retomado, já em sua potencialidade prevista inicialmente, desta vez estendida para nove escolas, quatro do campo e cinco urbanas.

Para que os participantes tivessem domínio teórico e técnico do que seria aplicado a professoras(es) e estudantes, foram organizados minicursos e oficinas sobre Educação Ambiental, divulgação e popularização da ciência, tecnologia, criatividade, narrativa transmídia. Como os universitários, em várias situações, iriam ministrar as oficinas aos adolescentes, era necessário promover a formação, e essa preparação foi feita em fase anterior ao início das atividades nas escolas, nas dependências da UFMT.

Como se tratava de uma proposta educomunicativa, cujo conteúdo seria disponibilizado em múltiplas plataformas, as produções eram de quatro naturezas: texto, foto, áudio e vídeo. Para isso, foram oferecidas sessões de oficinas a estudantes e a docentes, no sentido de orientar a respeito das técnicas do texto jornalístico, ângulo, plano, enquadramento e tratamento de imagens e realização, edição e disponibilização de vídeos. Como resultado das oficinas, os conteúdos elaborados fariam parte da narrativa transmídia.

Essa dinâmica reitera os principais conceitos da educação popular de Paulo Freire: o projeto partia do princípio de que todos comungam, cada qual nos seus respectivos contextos, de condições de contribuir na roda gigante da construção teórica, da sua aplicação, sem abrir mão da reflexão sobre as duas etapas anteriores, numa simbiose que Paulo Freire chamou de "práxis". 
O pano de fundo da nossa atuação nas escolas foi a constatação de que, em vez da supressão da internet e dos dispositivos digitais da sala de aula, é preciso pensar a educação escolar inserida em uma realidade que contemple as tecnologias, uma vez que elas já fazem parte do nosso dia a dia. De forma irremediável, será cada vez mais assim, em especial nas rotinas de jovens entre 14 e 17 anos, sujeitos de pesquisa dos nossos estudos.

A ideia das oficinas era justamente sugerir não apenas um cenário didáticopedagógico mais dinâmico, como também um momento de ajustes e adaptações, de acordo com a realidade de cada escola, resguardando igualmente os ineditismos da existência humana e das relações interpessoais, tendo em vista que, desde o início, a nossa pesquisa não teve como pressuposto levar um modelo terminado, em que não houvesse a possibilidade de moldar a argila.

O único pedaço do todo acabado era o pontapé inicial: uma reportagem especializada em ciência foi dada aos estudantes, que, a partir da leitura e discussão, detectaram as lacunas, os vácuos deixados pela história definida por Massarolo como "canônica". A continuidade, ou seja, o preenchimento dos vazios coube a textos, fotos, vídeos e áudios feitos pelas(os) estudantes, registrando nos seus respectivos ambientes de que forma aquela narrativa matriz se manifestava pontualmente. Acompanhando o projeto nas escolas, definitivamente sentimos na carne que o cerne da transmídia estava no grau de participação dos sujeitos envolvidos, da capacidade de atuação e da criação. Como no tecido complexo de Morin (2000), a transmídia exige que os diversos fios se entrelacem à tessitura das aprendizagens na reinvenção da educomunicação.

Para trabalhar com texto, foto, vídeo e áudio, a equipe do projeto foi dividida em vários times - formados por docentes e estudantes do curso de Comunicação Social da Universidade Federal de Mato Grosso. Essas turmas ficaram responsáveis por ministrar as oficinas, dividindo a atuação em diversas frentes, já que era preciso estar em duas escolas diferentes no mesmo dia.

Ao final, como resultado dos produtos gerados pelas oficinas, foram organizadas apresentações abertas com a presença de pais e integrantes da comunidade. O objetivo era marcar a finalização do projeto com a exposição pública do que havia sido produzido por estudantes. Jornais, documentários, matérias em áudio e imagens fotográficas, que tiveram alunas e alunos como produtores e participantes das 
atividades, compuseram a narrativa do conhecimento disponibilizada em diferentes plataformas de mídia.

No que concerne a uma das temáticas do projeto, o meio ambiente, as produções se preocuparam em captar as peculiaridades naturais de cada local - especialmente nas escolas rurais -, as características físicas das cidades - nos lugares em que as escolas estavam cravadas em municípios - e as práticas culturais de populações tradicionais. Dependendo do que cada sujeito percebe sobre o ambiente, sua interpretação se revela nos diversos meios que conseguem expressar. Assim, cada plataforma contava uma história do meio ambiente independente das demais, sem informações repetitivas.

\section{Educação popular e fenomenologia: a viabilidade do ser-mais}

O que se pretendeu nas ações do projeto foi conciliar a educação popular de Paulo Freire com a fenomenologia de Merleau-Ponty. As duas teorias, aos serem convertidas em métodos, trabalham em união numa espécie de simbiose: educadoras(es) e educandas(os) atuam em comunhão, sendo que a proposição das(os) primeiras(os) desafia a atuação das(os) segundas(os), que, por sua vez, fazem o mesmo. Tal como em uma ciranda, todas(os) se engajam e se encorajam em torno de uma ideia, a transformála constantemente.

Fizemos isso - e continuaremos a fazer nas nossas próximas investidas científicas - porque as Ciências Humanas não lidam com objetos inanimados, passivos e limitados a uma concepção a priori. O que para outras áreas do conhecimento se apresenta como objeto, para nós o entendimento é de que são sujeitos da pesquisa, porque além de responderem ao que propomos, também propõem. E é esse movimento que torna o carrossel constante com repetições e novidades.

Entendemos que nenhuma ideia é suficientemente acabada, que não possa ser transformada na relação das (os) envolvidas (os). Mesmo porque, uma vez considerada a proposta engessada, implica pressupor a incapacidade de outras pessoas modificarem os rumos do processo de acordo com suas carências, angustias e vontades. Fomentaríamos, assim, o prolongamento das opressões e dos abismos de desigualdades já consagrados na sociedade e que, a lamentar-se, a educação acaba reproduzindo. A nossa visão vai de encontro a isso.

De acordo com o filósofo francês Maurice Merleau-Ponty, a fenomenologia não tem como pretensão tornar universal, sem distinção de espaço e tempo, uma observação. 
A máxima fenomenológica vai na contramão disso. Ao valorizar a singularidade de cada sujeito e fenômeno, temos informações de escolas urbanas e rurais de Mato Grosso próprias daqueles contextos, com pessoas específicas, num intervalo de tempo determinado. Em outro momento, com pessoas diferentes, as impressões seriam distintas.

Essa dinâmica se dá porque o idealismo não tem força suficiente para construir solitariamente o conhecimento, assim como a experiência não é capaz, em isolamento, de traduzir as idiossincrasias da realidade. Indistintos, ideia e empirismo compõem a percepção, que mudará à medida que os olhos de quem investiga não forem os mesmos. A verdade não se encontra cá ou acolá, e sim na interação eu-outro-mundo.

\begin{abstract}
A aquisição mais importante da fenomenologia foi sem dúvida ter unido o extremo subjetivismo ao extremo objetivismo em sua noção do mundo ou da racionalidade. A racionalidade é exatamente proporcional às experiências nas quais ela se revela. Existe racionalidade, quer dizer: as perspectivas se confrontam, as percepções se confirmam, um sentido aparece. Mas ele não deve ser posto à parte, transformando em Espírito absoluto ou em mundo no sentido realista. $\mathrm{O}$ mundo fenomenológico é não o ser puro, mas o sentido que transparece na intersecção de minhas experiências, e na intersecção de minhas experiências com aquelas do outro, pela engrenagem de umas nas outras; ele é portanto inseparável da subjetividade e da intersubjetividade que formam sua unidade pela retomada de minhas experiências passadas em minhas experiências presentes, da experiência do outro na minha (MERLEAU-PONTY, 2011, p.18).
\end{abstract}

Entendendo que a filosofia de Paulo Freire conjuga a fenomenologia no campo da Educação, enunciando o que se define por pedagogia popular, lançamos mão desse binômio no projeto "Educomunicação, ciência e outros saberes: estudo do trabalho colaborativo em narrativas transmídias". A própria ideia de trabalho colaborativo, em que o (a) professor(a) apenas dá o pontapé inicial em uma sequência de atividades sobre a qual ele(a) passa a não ter controle, pois cada integrante do processo pedagógico pode encaminhar a história para um lado.

Temos, então, a inteligência coletiva - em que os (as) partícipes contribuem na construção da história, sem que se estabeleça a figura do(a) professor(a) como única proponente - agindo em comunhão com a cultura participativa e a égide da convergência midiática. Esse tripé, aliado à fenomenologia, permite aflorar a pedagogia freireana.

Esta é a razão pela qual, para nós, a "educação como prática da liberdade" não é a transferência ou a transmissão do saber nem da cultura; não é a extensão de conhecimentos técnicos; não é o ato de depositar informes ou fatos nos educandos; não é a "perpetuação dos valores de uma cultura dada"; 
não é o "esforço de adaptação do educando a seu meio". [...]Para nós, a "educação como prática da liberdade" é, sobretudo e antes de tudo, uma situação verdadeiramente gnosiológica. Aquela em que o ato cognoscente não termina no objeto cognoscível, visto que se comunica a outros sujeitos, igualmente cognoscentes.

Educador-educando e educando-educador, no processo educativo libertador, são ambos sujeitos cognoscentes diante de objetos cognoscíveis, que os mediatizam (FREIRE, 2013, p.106-107).

Inserir professoras (es) e estudantes em roda, rechaçando a lógica frente-fundo das salas de aula tradicionais, contribui para uma outra possibilidade de ambiente escolar. Dinamizando as atividades e os papeis de todos e todas, observamos a mudança de comportamento das (os) alunas(os) no sentido de se engajarem mais no dia a dia da escola. O trabalho conjunto entre professoras(es) e alunas(os) no decorrer do desenvolvimento do projeto como princípio basilar do processo colaborativo fez emergir o entendimento de que o encontro de sujeitos em uma convivência comum requer o reconhecimento da existência mútua. $\mathrm{O}$ ser humano somente "começa a existir pelo olhar do outro; ora, sem existência, a própria vida se extingue" (TODOROV, 2014, p.87). Ao ver no aluno um sujeito, o professor compartilha o seu conhecimento e é, por sua vez, também como sujeito reconhecido pelo aluno. Esta simbiose traz benefícios a todos. Mais ainda, exige para a sua consecução, encadeamento, um esforço constante de transparência, firmeza e afetos.

No momento atual, período de transição para a nova fase do projeto, há um consenso nas escolas rurais em relação à melhora na autoestima dos alunos(as), gosto pela leitura, relacionamento entre professores e alunos, envolvimento dos pais com a vida dos(as) estudantes na escola e um aumento na quantidade de discentes que querem estudar. Nas unidades escolares rurais participantes do projeto - as visitas às escolas urbanas acontecerão a seguir - houve, em 2016, aproveitamento no Enem superior ao do ano anterior, especialmente em redação. O bom rendimento permitiu o ingresso de vários(as) estudantes - mesmo os que não pretendiam dar seguimento aos estudos - em universidades públicas e privadas (nestas com 100\% de financiamento).

\section{Educomunicação ambiental e transmídia}

A crise instalada no meio ambiente, com as mudanças climáticas atingindo negativamente a vida de comunidades vulneráveis, é um desafio que está posto, cujo vetor crescimento econômico necessita ser encarado e debatido para que, em nome deste, não se atente contra as vidas humana, animal e vegetal. 
Chega-se, então, ao momento em que nos encontramos: partindo do conhecimento científico sobre as questões ambientais, entendemos ser necessário plantar os pressupostos e alternativas da Educação Ambiental em escolas da educação básica de Mato Grosso. Ao atuar junto a adolescentes e jovens estudantes, o projeto "Educomunicação, ciência e outros saberes" buscou, dentre outras finalidades, despertar o olhar de professoras(es) e alunas(os) para os problemas já em andamento.

Para que isso fosse possível, utilizamos como instrumento a narrativa transmídia. Partindo de princípios atuais do campo da comunicação, como convergência, participação e colaboração, propusemos a transmidialidade tal como um tabuleiro, enquanto as peças do jogo - as produções midiáticas viabilizadas por estudantes (áudio, vídeo, texto e foto) - foram disponibilizadas na plataforma digital, local em que atualmente as pessoas se encontram, majoritariamente a faixa de idade em questão no projeto.

Como pano de fundo, a educação popular de Paulo Freire e a fenomenologia de Maurice Merleau-Ponty serviram de metodologia para que tudo funcionasse sem o ordenamento rígido da estrutura escolar atual. Na compreensão de que o processo educacional é democrático e, por isso, as atividades são propostas e debatidas, assumindo que as experiências de docentes e estudantes contribuem para o enriquecimento das discussões em torno da transmidialidade.

Foi assim que os(as) proponentes do projeto levaram às escolas uma ideia apenas iniciada, porque em qualquer hipótese um modelo pode ser finalizado por determinadas pessoas num espaço específico e ser levado a realidades diferentes, cujas vivências são outras, sem que adequações sejam feitas.

O resultado foram produções que abordaram as peculiaridades de cada local, ora usando as técnicas oferecidas pelas oficinas do projeto, ora fazendo utilização de alternativas apresentadas pelas(os) próprias(os) estudantes. O mais importante dessa dinâmica foi perceber que é possível subverter o modelo atual didático-pedagógico, substituindo-o não só pela inserção da tecnologia em sala de aula, mas entendendo que as(os) alunos estão prontas(os) para assumir o protagonismo que pode revolucionar a educação e reverter os cenários de crise que nos ameaçam aqui e ali. 


\section{Referências}

BACHELARD, Gaston. A poética do espaço. Tradução: Antonio de Pádua Danesi. São Paulo: Martins Fontes, 1996.

CHAUI, Marilena. Convite à filosofia. 6.ed. São Paulo: Ática, 1987.

FREIRE, Paulo. Extensão ou comunicação. Tradução: Rosiska Darcy de Oliveira. 16.ed. Rio de Janeiro: Paz e Terra, 2013.

FREIRE, Paulo. Pedagogia da autonomia. 11.ed. Rio de Janeiro: Paz e Terra, 1996.

FREIRE, Paulo. Pedagogia do oprimido. 58.ed. Rio de Janeiro: Paz e Terra, 2014.

JABER, Michelle; SATO, Michèle; SILVA, Regina. Mapeamento social participativo: mundos entre a pesquisa educativa e o ativismo ecológico. Disponível em: <http://revistas.udc.es/index.php/RAS/article/view/799>. Acesso em: 05.out.2015.

JENKINS, Henry. Cultura da convergência. Tradução: Susana Alexandria. 2.ed. São Paulo: Aleph, 2009, 428p.

MASSAROLO, João Carlos. StorytellingTransmídia: narrativa para multiplataformas. Disponível em:

$<$ http://periodicos.uniso.br/ojs/index.php?journal=triade\&page=article\&op=view \&path $\% 5 \mathrm{~B} \% 5 \mathrm{D}=1764>$. Acesso em: 20.ago.2015.

MASSAROLO, João Carlos; MESQUITA, Dario. Narrativa transmídia e Educação: panorama e perspectivas. Disponível em:

$<$ https://www.revistaensinosuperior.gr.unicamp.br/edicoes/edicoes/ed09_abril2013/NM ES_3.pdf>. Acesso em: 20.ago.2015.

MERLEAU-PONTY, Maurice. Fenomenologia da percepção. Tradução: Carlos Alberto Ribeiro de Moura. 4.ed. São Paulo: WMF Martins Fontes, 2011.

MORIN, Edgar. Os sete saberes necessários à educação do futuro. Disponível em: <http://portal.mec.gov.br/seb/arquivos/pdf/EdgarMorin.pdf>. Acesso em: 07.out.2015.

PASSOS, Luiz Augusto; SATO, Michèle. Notas desafinadas do poder e do saber: qual a rima necessária à educação ambiental? Disponível em:

$<$ http://siaiweb06.univali.br/seer/index.php/rc/article/view/700>. Acesso em 06.out.2015.

SATO, Michèle. Debatendo os desafios da educação ambiental. Disponível em: <https://onedrive.live.com/view.aspx?cid=3BA61680D9F26D4B\&resid=3BA61680D9 F26D4B\%21145\&app=WordPdf $>$. Acesso em: 06.out.2015.

SATO, Michèle. Educação para o Ambiente Amazônico. Disponível em: <https://onedrive.live.com/view.aspx?cid=17DC7D667214610D\&resid=17DC7D66721 4610D\%21341\&app=WordPdf $>$. Acesso em: 04.jul.2016.

SILVA-MANFRINATE; André L.; SATO, Michèle. Entrelaçando educação ambiental e direito em ambiente de áreas úmidas: comunidade Pantaneira de São Pedro de 
Joselândia. Disponível em: 〈https://www.seer.furg.br/remea/article/view/3985/2471>. Acesso em: 05.out.2015.

SOARES, Ismar de Oliveira; VIANA, Claudemir Edson. Pais, filhos e internet: a pesquisa TicKids Online Brasil 2012, na perspectiva da Educomunicação. Disponível em: <http://issuu.com/abpeducom/docs/tic-kids-online-2012_claudemir_isma>. Acesso em: 12.out.2015.

TODOROV, Tzvetan. A vida em Comum: ensaio de Antropologia geral. 1. Ed. São Paulo: UNESP, 2014. 